$41(3) \mid 2012$

Recomposiciones territoriales de las periferias de las metrópolis andinas

\title{
Estrategias espaciales en la provisión de vivienda estatal popular en un contexto neoliberal. El caso de la periferia bogotana
}

Stratégies spatiales de l'offre de logements sociaux dans un contexte néolibéral.

Le cas de la périphérie de Bogotá

Spatial strategies in the provision of state sponsored low-income housing in a neo-liberal context: a case from the periphery of Bogotá

\section{Sara Milena Roa Muñoz}

\section{OpenEdition}

Journals

Edición electrónica

URL: http://journals.openedition.org/bifea/284

DOI: 10.4000/bifea.284

ISSN: 2076-5827

Editor

Institut Français d'Études Andines

Edición impresa

Fecha de publicación: 31 diciembre 2012

Paginación: 417-439

ISSN: 0303-7495

Referencia electrónica

Sara Milena Roa Muñoz, «Estrategias espaciales en la provisión de vivienda estatal popular en un contexto neoliberal. El caso de la periferia bogotana », Bulletin de l'Institut français d'études andines [En línea], 41 (3) | 2012, Publicado el 01 agosto 2013, consultado el 06 noviembre 2020. URL : http:// journals.openedition.org/bifea/284; DOI : https://doi.org/10.4000/bifea.284

Les contenus du Bulletin de l'Institut français d'études andines sont mis à disposition selon les termes de la licence Creative Commons Attribution - Pas d'Utilisation Commerciale - Pas de Modification 4.0 International. 


\title{
Estrategias espaciales en la provisión de vivienda estatal popular en un contexto neoliberal. El caso de la periferia bogotana
}

\author{
Sara Milena Roa Muñoz*
}

\begin{abstract}
Resumen
El problema habitacional en Bogotá ha sido una constante a lo largo del siglo XX y lo que va del siglo XXI, situación que ha generado la respuesta estatal de crear soluciones de vivienda que atiendan dicho déficit. Esta respuesta se puede diferenciar en dos periodos: antes y después de la implantación del modelo neoliberal en el país. El presente trabajo se centra en el análisis de la producción de vivienda popular en Bogotá en el periodo neoliberal. El principal objetivo es caracterizar los mecanismos y la legislación estatal de acceso a la vivienda, la clasificación de estos proyectos urbanísticos, y su ubicación en la periferia sur y suroccidental bogotana.
\end{abstract}

Palabras clave: neoliberalismo, globalización, provisión de vivienda, Vivienda de Interés Social, Vivienda de Interés Prioritario, Subsidio Familiar de Vivienda

\section{Stratégies spatiales de l'offre de logements sociaux dans un contexte néolibéral. Le cas de la périphérie de Bogotá}

\section{Résumé}

Le problème du logement à Bogotá a été une constante tout au long du 20ème siècle et du début du 21ème. C'est répondre à ce déficit que l'État a engagé une action en matière de construction de logements. II est possible d'en distinguer deux phases : avant et après la mise en œuvre du modèle néolibéral dans le pays. Cet article a pour objet l'analyse de la production de logements sociaux à

* Licenciada en Ciencias Sociales de la Universidad Pedagógica Nacional, especialista en Análisis espacial y estudiante de la Maestría en Geografía de la Universidad Nacional de Colombia. Bogotá, Colombia. E-mail: sarita_milenita@yahoo.es 
Bogotá au cours de la deuxième période, la période néolibérale. Le principal objectif est de caractériser les mécanismes et la législation étatique définissant l'accès au logement ainsi que de réaliser une classification des projets urbanistiques, localisés dans les périphéries sud et sud-occidentales de Bogotá.

Mots clés : néolibéralisme, globalisation, offre de logements, logements sociaux, logements prioritaires, Subvention familiale pour l'accès au logement

\title{
Spatial strategies in the provision of state sponsored low-income housing in a neo-liberal context: a case from the periphery of Bogotá
}

\begin{abstract}
The housing problem in Bogotá has been constant throughout the twentieth century and so far during XXI century, a situation that has led the government response to create housing solutions that address this deficit., The response can be differentiated in two period:, before and following the implantation of the neoliberal model in the country. This work focuses on the analysis of the production of popular housing in Bogotá during the neoliberal period. The main objective is to characterize the mechanisms and state legislation providing access to housing, the classification these urban projects and their location in the southern and southwestern periphery of Bogota.
\end{abstract}

Key Words: Neoliberalism, globalization, provision of state housing, public housing, priority housing, family allocation for housing

\section{INTRODUCCIÓN}

Aunque actualmente es evidente un claro desaceleramiento en torno al crecimiento endógeno de las metrópolis a nivel latinoamericano, estas siguen aumentando su crecimiento espacial. Es aquí cuando se incrementan los fenómenos de segregación espacial en las ciudades. Se considera aquí la segregación como una problemática que evidencia cómo los grupos desfavorecidos se alejan de los recursos de la ciudad, generando procesos de exclusión territorial por la creación de límites socioespaciales; esta se caracteriza actualmente por la expulsión del centro de las clases menos favorecidas debido a factores económicos evidenciados en el valor que adquiere el suelo (Dureau et al., 2007: Parte I y III).

En este sentido, se evidencia una clara particularidad en la formación de las principales urbes colombianas. En nuestro caso específico, la ciudad de Bogotá ha presentado a lo largo del siglo XX un constante y rápido crecimiento, ocasionado por dos factores fundamentales. El primero de ellos lo constituyen los problemas de violencia que se han presentado en Colombia, los cuales han ocasionado un alto porcentaje de migraciones campo-ciudad por medio del desplazamiento forzado. Bogotá, como ciudad capital, ha sido la receptora en mayor medida de dicha afluencia de desplazados, iniciada a principios del siglo XX, la cual, lamentablemente, no ha cesado hasta nuestros días.

Esta problemática se caracteriza principalmente por tres momentos históricos: 
1) las primeras guerras entre liberales y conservadores a principios de siglo, las cuales marcaron el surgimiento de los primeros barrios obreros hacia el sur oriente;

2) la época conocida como la Violencia, a mediados del mismo siglo, que impulsó el poblamiento de la periferia sur, norte y occidental de la ciudad, con campesinos provenientes de los Santanderes, Boyacá, Cundinamarca y Tolima, principalmente;

3) finalizando el siglo y comenzando el presente, la agudización del conflicto, que ha generado nuevamente un masivo desplazamiento hacia las cabeceras municipales, donde Bogotá ha sido receptora de gran cantidad de población.

El estatus de ciudad capital con el que cuenta Bogotá también ha ocasionado el segundo factor fundamental de crecimiento, ya que crea una fuerte atracción de los habitantes de sectores rurales del país, que viajan a ella motivados por la idea de progreso, acceso a fuentes de trabajo y educación. No obstante, en palabras de Dureau \& Gouëset

«[e]l crecimiento urbano, ampliamente exógeno, rápidamente ha respondido a una lógica más endógena, y ha encontrado sus propias fuerzas en el dinamismo demográfico de poblaciones urbanas jóvenes y fecundas» (Dureau et al., 2007:13).

La situación señalada anteriormente, inherente al desarrollo de las ciudades latinoamericanas, se ha visto estimulada en las dos últimas décadas por el ingreso del neoliberalismo y, consecuentemente, por el surgimiento de la capital como epicentro de actividades financieras y bursátiles, las cuales han dinamizado cada vez más la economía y aumentado la atracción de población en torno a dichas actividades. Los factores antes mencionados generan constantemente la creación de políticas públicas y respuestas estatales que buscan satisfacer las necesidades habitacionales de las nuevas familias bogotanas.

El tema estatal obliga a profundizar en el análisis de las doctrinas político-económicas que han dirigido el accionar del Estado a lo largo del siglo XX y los inicios del XXI. En este sentido, para este artículo, la temática se aborda en un primer apartado analizando el concepto de neoliberalismo, su influencia político-económica sobre los Estados y su efecto sobre los espacios urbanos. Desde esta perspectiva, se tiene que el neoliberalismo se impuso como doctrina político económica en Colombia desde la década de los noventa con la apertura económica efectuada en el país. Sin embargo, desde años atrás se fueron adoptando medidas que luego serían reconocidas como neoliberales, principalmente en los ámbitos comercial y de edificación de vivienda. Este último con la reducción de la participación estatal desde la década de 1970 y la primacía de corporaciones de ahorro y crédito para fomentar la construcción urbanística (Espinoza, 2007: 65). Básicamente, el neoliberalismo se basa en un debilitamiento del papel del Estado como ente regulador de la economía, lo que consecuentemente genera un fortalecimiento del papel de la empresa privada en las funciones antes estatales. Asimismo, la influencia del neoliberalismo sobre el espacio recae en una mercantilización 
del suelo, por lo tanto, durante el periodo neoliberal el suelo se ve sometido a los precios que le otorga una especulación económica mucho más fuerte, en comparación con el modelo keynesiano, y consecuentemente dichos precios tienden a ser decisivos en las políticas que se adelanten sobre el espacio.

Partiendo entonces del cambio político-económico que ha generado el paso del modelo keynesiano de Estado de bienestar al modelo neoliberal, se pretende analizar el papel del Estado y su labor en cuanto a la provisión de vivienda, identificando cómo han cambiando las formas de otorgar dicho bien y la ubicación e infraestructura del mismo. De esta manera se verá cómo, a mediados del siglo $X X$, se evidencia dentro del modelo de Estado keynesiano la construcción en Bogotá de los primeros barrios y ciudadelas destinados a la clase obrera, con casas amplias, algunos incluso centrales y gestionados por medio de entidades estatales. Luego, con la entrada y el auge del neoliberalismo, se encuentra una provisión de vivienda mediada no por las necesidades de la población sino por las imposiciones del capital, el cual determina el lugar de ubicación del proyecto urbanístico según los bajos costos del suelo, los materiales a emplear, el tamaño de las viviendas y, claro, la intervención de empresas privadas dentro del proceso (Molina, 2007; Espinosa, 2007).

Por ende, se analizará brevemente cómo se llevó a cabo la provisión de vivienda dentro del modelo Keynesiano en Bogotá, para finalizar caracterizando la clara influencia neoliberal, evidenciada en los proyectos de Vivienda de Interés Social y Vivienda de Interés Prioritario que actualmente se agencian en Bogotá. Dicha problemática se abre al análisis en torno a la ubicación de la vivienda, las formas de proveerla y sus características físicas1.

De esta forma, se elaboraron gráficos en torno a la provisión de vivienda y cartografía, en relación con la ubicación de dichos proyectos, su acceso a vías y sistemas de transporte, la estratificación del suelo donde se ubican y la relación entre ubicación y valor de las viviendas.

\section{CAPITALISMO NEOLIBERAL Y ESPACIO URBANO}

La influencia del capitalismo sobre el espacio radica básicamente en la mercantilización del suelo:

«el suelo y las mejoras realizadas en él son en la economía capitalista contemporánea, mercancías» (Harvey, 1985: 163).

Debido a que el suelo se convierte en un bien imprescindible en tanto que es

1 Para este fin, se realizó un análisis a partir de datos obtenidos sobre la provisión de vivienda nueva en Bogotá, la oferta de Vivienda de Interés Social y prioritario, agenciada desde la caja de compensación familiar Colsubsidio, así como la creación, funcionamiento y alcance de Metrovivienda como empresa social y comercial del Distrito; igualmente, se tuvo en cuenta el Decreto 4466 de 2007, el cual reglamenta la normatividad para la Vivienda de Interés Social. 
el lugar en el que se inscriben las acciones realizadas sobre el espacio, adquiere su valor y condiciona sus precios, representando grandes esfuerzos y formas de acceder a él por parte de los demandantes. En palabras de Harvey

«el suelo y sus mejoras son mercancías de las que ninguna persona puede prescindir. Yo no puedo existir sin ocupar un espacio, no puedo trabajar sin ocupar un lugar y sin hacer uso de los objetos materiales localizados en ese lugar y no puedo vivir sin una vivienda del tipo que sea» (Harvey, 1985: 164).

Entonces, la demanda del suelo se mantiene siempre constante y activa en la mayoría de casos, razón por la cual la construcción urbana se convierte en un elemento dinamizador en la economía.

Como toda mercancía, el suelo se ve sujeto al valor de uso que le otorga la localización. De esta manera, la localización próxima o lejana de centros culturales, zonas comerciales, zonas residenciales, lugares de trabajo, avenidas, focos de polución, zonas de aglomeración, delincuencia, entre otras, es la que genera el valor de uso del suelo, teniendo en cuenta que además el suelo obtiene su precio según el costo del recorrido de distancias necesarias básicas, así como el estatus que genera la ubicación en él y, en este sentido, la cercanía al centro o a los principales centros económicos, culturales y prestadores de servicios de la ciudad (Harvey, 1985: 165, 166). Por consiguiente, son los espacios relegados a las periferias, los que frecuentemente presentan no solo largas distancias hacia el centro de la ciudad, sino también problemáticas ambientales, sociales y, consecuentemente, económicas.

Dentro del capitalismo neoliberal, el suelo es susceptible de una monopolización por parte de entes especuladores que lo someten al libre mercado, negando su redistribución equitativa en una población, donde los política y económicamente débiles serán los más afectados (Harvey, 1985). De igual forma, el valor del suelo y la especulación organizan el espacio, ya que estos factores son los que ubican en lugares prestigiosos (esto es, con óptimas condiciones ambientales, fácil acceso a vías, cercanía a centros de trabajo, comerciales y culturales) a las clases opulentas de la ciudad; en las zonas estratégicas, con vías de acceso cercanas a aeropuertos y centros administrativos, se ubican las empresas y hoteles; en las zonas con baja restricción ambiental, las industrias, y en las zonas de menor precio por condiciones ambientales (contaminación, formas del suelo), de lejanía a los centros laborales y de servicios, a los económicamente débiles. En palabras de Torres (2009: 275) «el modelo de desarrollo neoliberal... subordina la planificación territorial a las lógicas del mercado», esto con el fin de crear aún mayor ganancia para el sector privado, como argumenta también Pradilla (2009: 299), quien afirma que

«pasamos del monopolio estatal planificable y controlable política y socialmente, al incontrolable y no planificable monopolio privado, con su mercado cautivo de la necesidad y sus sobre ganancias monopólicas».

Se evidencia, entonces, la presencia y agudización de fronteras que generan segregación socioespacial dentro del espacio urbano, segregación que ha sido creada por medio de dinámicas de expulsión de población de algunos sectores en 
la ciudad, a través de procesos de especulación y encarecimiento del suelo urbano disponible y de la inversión sobre el mismo, lo que hace que se distingan las zonas formales de las informales, es decir, zonas diferenciadas no solo por elementos sociales y económicos, sino también por aspectos espaciales y urbanísticos (Torres \& Rincón, 2011: 22, 35, 71).

El doble costo que acarrea la mala calidad de las vías de acceso a sus residencias, la distancia en relación a los centros económicos, el complejo acceso a los servicios, hace que en su mayoría los económicamente débiles salgan solo de los espacios en los que habitan cuando es estrictamente necesario, mas no cuando lo deseen. Tal situación aumenta la presencia de zonas marginales que, aunque coexisten por medio de una relación simbiótica con zonas céntricas marcada por relaciones laborales, tanto formales como informales, se distinguen claramente unas de las otras, diferenciando de manera evidente las relaciones y las clases sociales, y aumentando la desigualdad.

La especulación del suelo urbano dentro del capitalismo neoliberal es cada vez más fuerte. Las prácticas monopólicas especulativas del suelo, donde, por medio de la «sustracción de la tierra por parte de terratenientes urbanos... se mantienen deliberadamente vacíos grandes lotes de terrenos urbanizables al interior de ciudades, haciendo utilización parasitaria de la inversión estatal en infraestructura de vías y servicios públicos, con tal de valorizarlos hacia el futuro» (Espinosa, 2009: 196), crean una escasez ficticia de tierras para urbanización, aumentando la periferización de la vivienda urbana o la ubican de difíciles condiciones ambientales. Eso se debe a que se destina, para el caso de la vivienda popular, el aprovechamiento de suelos a través de la eliminación de importantes reservas naturales como (en el caso de Bogotá) los humedales, las rondas de los ríos y la vegetación de los cerros para la construcción, o, por otro lado, se urbanizan los espacios rurales existentes en la ciudad.

La escasez y el aumento en el valor del suelo urbano también se generan por la declaración de algunas zonas de reserva ecológica, como es el caso del parque Mirador de los Nevados en la localidad de Suba o la Reserva Forestal Regional Productora del Norte de Bogotá, ubicada en las localidades de Suba y Usaquén. Estas zonas son de alta importancia ecológica, pertinentes y necesarias en una ciudad que aumenta cada vez más sus niveles de contaminación, pero, consecuentemente, son zonas que encarecen el suelo en tanto limitan su disponibilidad para construcción de viviendas al interior de su perímetro. Asimismo la afluencia de migrantes hacia la ciudad y el crecimiento vegetativo de la misma son factores que aumentan la demanda de vivienda en todas las clases sociales, en una ciudad donde cada vez se encuentra más reducido el espacio urbanizable, por condiciones económicas o ecológicas.

En cifras, «en el caso bogotano se conforman 50834 hogares anualmente y solamente son atendidas por el mercado 29700 viviendas para las necesidades creadas» (Torres, 2009: 264). Lo anterior denota entonces un déficit cuantitativo que conduce a la autoproducción de vivienda como forma de solucionar dicha dificultad por gran cantidad de familias bogotanas. Igualmente, las cifras citadas 
más arriba llevan a preguntarse icómo se atienden estas soluciones de vivienda en la ciudad dentro de las dinámicas del neoliberalismo?, pregunta que se abordará en el próximo punto.

Por lo tanto, vale la pena tener en cuenta en este aparte algunos de los aspectos más sobresalientes del modelo neoliberal. Dicho sistema, basado en las políticas liberales del siglo XIX, aplica la teoría de «la mano invisible del mercado», planteada por Adam Smith. La propuesta ética de dicho sistema, evidenciada en las políticas agenciadas por el Consenso de Washington en la década de 1990 (Vega, 2007), se basa en la primacía de la libertad y los derechos individuales sobre los colectivos. En este sentido, cobran significativa importancia el derecho a la propiedad privada y la libre acumulación. David Harvey hace referencia a este punto, considerando al neoliberalismo como

«una teoría de prácticas político-económicas que afirma que la mejor manera de promover el bienestar del ser humano consiste en no restringir el libre desarrollo de las capacidades y de las libertades empresariales del individuo dentro de un marco institucional caracterizado por derechos de propiedad privada fuertes, mercados libres y libertad de comercio« (Harvey, 2007: 6).

El papel del Estado dentro de este sistema, tal y como lo propone el Consenso de Washington, es el de un mero ente facilitador. Por ende, dentro del neoliberalismo el Estado es un regulador que, a diferencia del Estado benefactor keynesiano, no reconoce como su responsabilidad la salud, la educación, el empleo, la vivienda, e incluso la industria $y$, por consiguiente, las entrega a la empresa privada, siendo únicamente un mediador que debe garantizar las condiciones para la buena competencia y el funcionamiento del mercado, así como los derechos a la propiedad privada. Se hace evidente, entonces, cómo en el neoliberalismo prima la economía política sobre la social, en tanto, obtiene mayor importancia el mercado sobre las políticas públicas de bienestar social. De esta manera queda claro cómo se deja a la regulación (o más bien desregulación) de las fuerzas del mercado básicamente las tasas de interés, la oferta, la demanda y el tipo de cambio. En este contexto, el suelo es convertido en mercancía y pasa a ser manejado por las fuerzas del mercado.

De la misma manera el Gobierno, entendido como la forma de dirigir un Estado, cambia sustancialmente con el neoliberalismo. Si bien se tiene que dentro del Estado keynesiano el Gobierno se basaba en un poder estatal por sí mismo, en el nuevo sistema se transforma en la denominada gobernanza, donde se aumenta la noción de Estado agregándole elementos de la sociedad civil (Harvey, 2007: 86). En este sentido, dentro de las decisiones estatales en el nuevo sistema, infieren elementos como grupos económicos, empresas y demás actores interesados ya sea en la protección de los mercados, las regulaciones económicas, los derechos a la propiedad o en el manejo de las responsabilidades sociales.

Jolly (2010: 32), afirma cómo «la gobernancia [sic]... considera el territorio como una construcción social» en la cual deben intervenir todos los actores sociales que se encuentren presentes en él, por ende, aclara cómo dentro de las propuestas de la gobernancia [sic] urbana surgen las políticas públicas. Un ejemplo es el caso 
de la Vivienda de Interés Social, a modo de gobernar y administrar el territorio, con la participación de diferentes actores pertenecientes a la sociedad civil, con el fin de atender la problemática habitacional. Entonces la «gobernanza urbana» es un método que se pretende más incluyente, en tanto considera que «el poder para organizar el espacio deriva de todo un complejo de fuerzas movilizadas por diversos agentes sociales» (Harvey, 2001: 372).

Esas otras fuerzas, movilizadas por diversos agentes sociales, son las fuerzas de la empresa privada y diferentes agentes económicos que regulan por parte del Estado el espacio, y lo que buscan principalmente es hacer atractivo el lugar para la inversión extranjera por medio de un buen clima empresarial. Ahora, el tema nos introduce en los efectos de la globalización sobre el espacio urbano. Si la característica básica del capitalismo neoliberal es la especulación sobre el valor del suelo, la cual aumenta la segregación, es similar a la característica de la globalización, que crea archipiélagos financieros, que no son otra cosa que la configuración de redes y nodos, «estructura básica del despliegue y reescalamiento capitalista» (De Mattos, 2009: 42).

En este sentido, el capitalismo global genera ciertas características similares en las principales ciudades latinoamericanas, evidenciadas en problemáticas como la segregación. También la creación y el aumento de zonas francas (lugares a los que llegan las mercancías del extranjero y esperan su respectiva legalización), la aparición cada vez más continua de centros comerciales o shoping centers, y la centralización de los principales servicios económicos, evidencian la existencia de archipiélagos económicos al interior de la ciudad. Es importante recalcar en este punto que las metrópolis ya no tienen como tal un centro, sino varios centros funcionales, aportando entonces a la diferenciación espacial y social por medio del valor del suelo, fenómeno característico del neoliberalismo.

Finalmente, se entiende cómo la mercantilización del suelo antes mencionada, no solo influye en la organización espacial si no que también aumenta la brecha de segregación socioespacial en la ciudad. A diferencia de ciudades como Santiago de Chile, donde en un mismo espacio se tienden a ubicar diferentes estratos sociales (Hidalgo, 2011: 81), en Bogotá cada vez más se destinan las periferias para albergar a las clases populares, en tanto las zonas céntricas urbanas o con altos beneficios de la ciudad, solo permiten su acceso a los habitantes o entidades que tienen con que pagarlo.

\section{PROVISIÓN DE VIVIENDA, ESTADO Y ESPACIO URBANO, EL CASO DEL DISTRITO CAPITAL}

Históricamente, la provisión de vivienda en la capital colombiana ha estado acompañada por el déficit habitacional. A través de los años, los bogotanos con menos recursos han solucionado sus problemas de vivienda de manera autónoma, ejerciendo procesos de autoconstrucción de vivienda en predios con cierto grado de asequibilidad para las clases bajas de la ciudad. El común de estos predios es su marginalización y periferización, además de las malas condiciones ambientales 
que presentan, siendo ubicados en zonas de ladera, rondas de los ríos, faldas de las montañas, canteras, chircales, entre otros. De esta manera se han constituido gran cantidad de barrios informales en la ciudad. Frente a dicha situación, el Estado ha atendido la problemática a través de planes de vivienda popular que pretenden mejorar las condiciones y el estilo de vida de las clases populares a través de la provisión de una vivienda que brinde a sus ocupantes la satisfacción de un hogar propio, con los suministros de servicios básicos.

Este ha sido el panorama permanente de la ciudad. Sin embargo, la atención desde el Estado hacia los proyectos urbanizadores de provisión de vivienda se diferencia fácilmente en dos épocas, que se pueden enmarcar en el antes y después de la implantación del proceso neoliberal en el país. Es así como la provisión de vivienda durante el siglo XX se caracterizó por la creación de diversas entidades y parámetros estatales que se encargaban de la normatización, construcción y financiación de los proyectos urbanísticos. Cabe aclarar que hasta 1991 la construcción y venta de vivienda se realizó de manera directa por parte del Estado, a través de las entidades creadas para tal fin. Es así como surgen la Junta de Habitaciones para Obreros en 1919, el Banco Central Hipotecario en 1932, el Instituto de Crédito Territorial en 1938 y la Caja de Vivienda Popular en 1942 y de manera legislativa, la ley de vivienda obrera (ley 65) de 1936.

Igualmente, es importante tener en cuenta que aunque la urbanización informal y los barrios de estratos bajos se encuentran en toda Bogotá, tradicionalmente se han ubicado hacia el norte los barrios de estratos altos, relegando al sur las tierras de bajos costos «óptimas» para la construcción de vivienda popular y obrera. Es así como

«la localización en el plano de la ciudad de los proyectos de vivienda realizados por las instituciones encargadas de atender la población de escasos recursos muestra cómo, hasta los años 60, los sitios escogidos se localizaron en el sur y occidente de la ciudad, y sólo después de 1970 hay un volumen considerable de proyectos localizados en el noroccidente» (CCVL, 1996: 100).

En el mismo sentido, con el fin de lograr una clasificación de los bienes inmuebles en Colombia, se inicia en 1983 el proceso de implementación de la estratificación socioeconómica, con el fin de cobrar de manera diferencial los servicios públicos domiciliarios (Alzate, 2006: 11). De esta forma la zonificación urbana pasó a representarse en estratos socioeconómicos, definiendo el tipo de área residencial en estratos 1 y 2 que cubren las áreas más pobres dentro de la categoría de estrato bajo, estratos 3 y 4 que manejan los sectores de ingresos medios-bajos y mediosmedios y los estratos 5 y 6 que cubren los sectores residenciales de altos ingresos, medio alto y alto.

La concepción dentro de la lógica keynesiana, característica de la época de los años 1950, 1960 y 1970, de mejorar y dignificar la calidad de vida de los obreros por medio del Estado de bienestar, permeó la producción de vivienda urbana, la cual se basaba no solo en dar un sitio para la vivienda del obrero, sino en dar un sitio que dignificara su calidad de vida y agrupara a su familia, que para la 
época eran bastante numerosas. Esto influiría de manera positiva en los estándares de desarrollo del país. Por lo tanto, dentro de los parámetros para acceder a la vivienda, necesarios en tanto era mayor la demanda por los hogares que la oferta presentada, se encontraban condiciones como la cantidad de hijos. Las familias con más hijos tenían prelación en la adquisición de vivienda (Chela, 1997).

Igualmente, el tamaño de estas viviendas no solo correspondía al tamaño de la familia, sino que, favorecidas por las grandes cantidades de lotes urbanizables con que contaba la ciudad, y con la noción que para ese entonces se tenía de espacio vital, entendido como el espacio necesario para vivir óptimamente, se construían viviendas de gran tamaño. El tamaño fue reglamentado por el acuerdo 51 de 1963, por medio del cual produjeron viviendas de un área mínima de $120 \mathrm{~m}^{2}$ con un frente mínimo de $6 \mathrm{~m}$, una altura máxima de dos pisos y un área máxima aproximada de 80 y $90 \mathrm{~m}^{2}$; estas nuevas urbanizaciones recibieron el nombre de «Barrios de normas mínimas» (CCVL, 1996: 100).

Sin embargo, la reducción ficticia del espacio urbanizable bogotano por medio de los lotes de engorde ubicados en la ciudad, pertenecientes a la especulación de terratenientes urbanos que aumentan los costos del suelo, y la necesidad de producir más viviendas a menor costo, con el fin de suplir la demanda, propició la reglamentación del decreto 2489 de 1980 y su artículo 110. Este decreto fijó la norma para lotes bifamiliares, es decir, el aprovechamiento de un lote para dos familias. Cada predio fue dividido en dos lotes independientes y se establecieron las áreas mínima y máxima de los predios en 60 y 90 m², con una altura máxima de tres pisos. Eso generó la creación de lotes de 3 metros de frente por 12 metros de fondo, característicos en las urbanizaciones de vivienda popular de los años 1980 y 1990 (CCVL, 1996: 101). Dicho decreto se puede considerar como uno de los predecesores a la lógica neoliberal y su impacto en el suelo urbano, en tanto se enmarca en la noción de aumento de la productividad del suelo.

La mercantilización de la vivienda popular se empezaría a ejecutar en 1972 con los decretos 677 y 678, los cuales marcaron un cambio en los sistemas de financiación de la vivienda, en tanto se crearon la Junta de Ahorro y Vivienda y el Fondo de Ahorro y Vivienda, FAVI, del Banco de la República, el cuál opero dentro del sistema de «valor constante» (Espinosa, 2007: 64). De esta manera, se autorizó la constitución de corporaciones privadas de ahorro y vivienda, encargadas de promover ahorro privado para la construcción. Estas corporaciones fueron las que financiaron, desde esta época, los programas de vivienda agenciados por el sector privado.

En este contexto se creó el sistema de unidades de poder adquisitivo constante, UPAC, que «pretendía proteger la inversión, cubrir la inflación e incentivar el crédito, favoreciendo todo esto al sector de la construcción y al financiero, ya que se generaría demanda de créditos para la compra de viviendas» (Mora, 2010: 17). Lo anterior se basaba en una política de reactivación económica, que encabezaba el presidente de la república de ese entonces, Misael Pastrana. Es evidente entonces, cómo el sector de la construcción, y los incentivos hacia el mismo, han sido utilizados en las últimas décadas para reactivar la economía en Colombia. Como efecto posterior a la creación del UPAC, la financiación de 
vivienda terminó dirigiéndose hacia los sectores medios, los cuales estaban en capacidad de cubrir los préstamos de sus viviendas.

A continuación, se presentan cuatro planos, a escala real, con el fin de ilustrar dicha reducción de espacio. Los tres primeros son proyectos de vivienda del Instituto de Crédito Territorial: el Centro Antonio Nariño de 1958, con una extensión aproximada de 103 m², Ciudad Kennedy de la década de 1960 con una extensión aproximada de $69 \mathrm{~m}^{2}$, Ciudad Tunal de 1972 con una extensión aproximada de 68 $\mathrm{m}^{2}$. El último es un proyecto de la Caja de Compensación Familiar2 Colsubsidio: el proyecto Maiporé de 2010, con una extensión de 42,5 m².

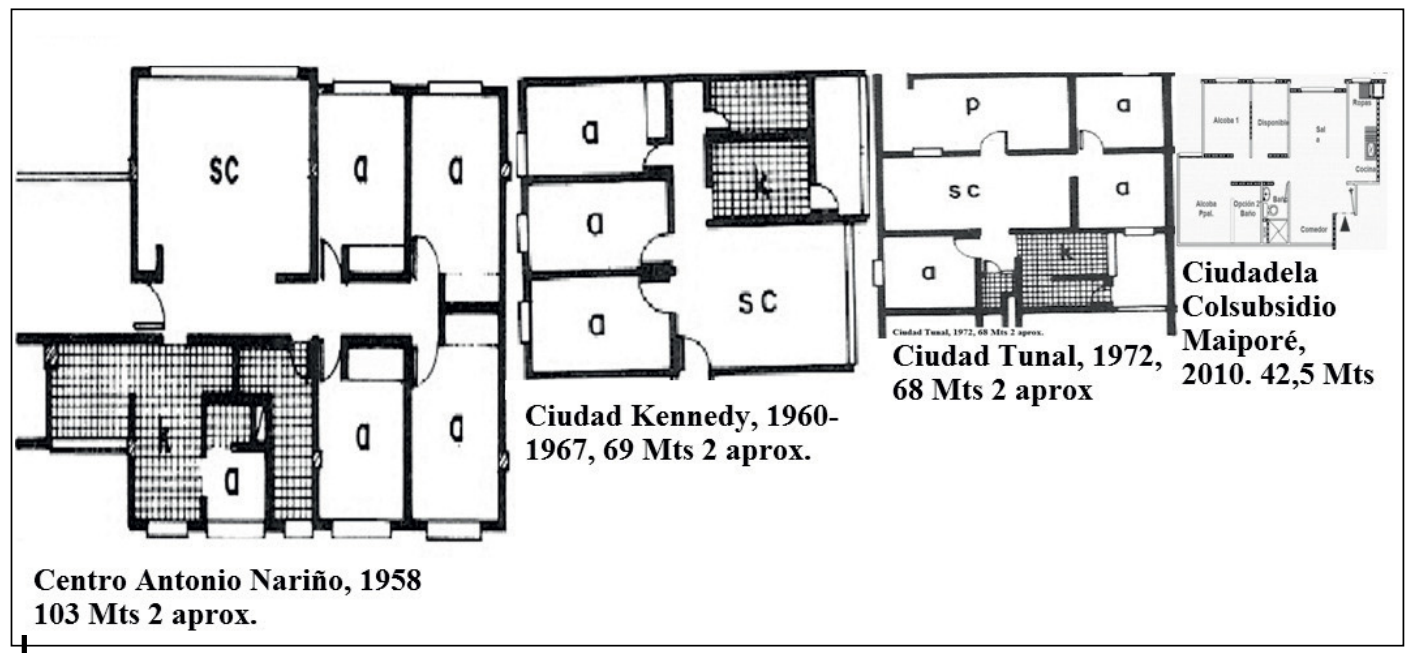

Figura 1 - Reducción progresiva del tamaño de las viviendas

Como se evidencia en los planos, la primacía de espacios amplios con áreas sociales y habitaciones de buen tamaño se fue minimizando con el transcurrir de los años, presentando actualmente una reducción drástica en tales lugares. El aprovechamiento del espacio ha llevado a una clara disminución de los espacios sociales, los cuales actualmente se mantienen en viviendas de alto costo y estratificación. En concordancia con el nuevo modo de vida y las necesidades socioeconómicas, en las que priman el trabajo o la subsistencia económica sobre las labores de casa, tienden a reducirse los espacios de la cocina y el patio de ropas, este último contando con el avance tecnológico de la lavadora, que se

2 Las Cajas de compensación familiar son unas entidades privadas que surgieron por la legislación colombiana para mejorar la calidad de vida de los trabajadores. Recaudan dinero que les aportan las empresas, y brindan a los trabajadores beneficios como una cuota monetaria conocida como subsidio familiar de vivienda, recreación, salud y soluciones de vivienda. 
vuelve imprescindible en este nuevo tipo de viviendas. Se podría decir que incluso este nuevo tipo de viviendas ha modificado los estilos de vida cotidiana: ya no es posible realizar grandes fiestas en estas viviendas. Por lo tanto ha cambiado completamente la lógica de los salones comunales, los cuales fueron construidos como un espacio para la reunión de la comunidad barrial y la oferta de actividades y servicios hacia la misma, pasando a ser lugares de alquiler para la realización de fiestas familiares.

De igual forma, se reduce el tamaño de los dormitorios: las nuevas viviendas populares ofrecen habitaciones de un área reducida que obliga a ubicar dentro de ellas lo estrictamente necesario. Se destaca en esta nueva producción de vivienda, el aprovechamiento del espacio vertical, ofreciendo para las casas dos o tres pisos con un tamaño aproximado de $12 \mathrm{~m}^{2}$, una alcoba por piso. Aunque, se evidencie la construcción de edificios de apartamentos desde la década de 1950, estos se masificarán en la década de 1980, contando con un área destinada en los proyectos de vivienda popular desde los 32 hasta los $60 \mathrm{~m}^{2}$.

Debido a la importancia que adquiere el valor del suelo en las épocas del capitalismo neoliberal, se ve claramente cómo el tamaño de la vivienda va ligado a su valor. En este sentido, aunque el valor de la vivienda depende de la zona en la que se encuentra localizada, también influye su tamaño sobre dicho valor. Las siguientes gráficas, realizadas con los datos obtenidos en la revista Metro Cuadrado, y que relacionan algunos proyectos de vivienda nueva en venta en Bogotá para octubre de 2007, especifican cómo influye directamente el tamaño del inmueble sobre su valor.

Según los gráficos, se evidencia cómo en las zona Norte-Centro-Chapinero que comprende las localidades de Usaquén, Chapinero, Santafé y Candelaria, el área máxima de las viviendas en venta llega a los $400 \mathrm{~m}^{2}$ con un valor máximo de \$1 124 000,000. Una situación similar existe en la zona noroccidente que comprende las localidades de Suba y Engativá, en la que el tamaño máximo de las viviendas es aproximadamente similar, aunque se evidencia una mayor heterogeneidad en la provisión de las viviendas; el precio máximo llega a los ochocientos treinta y cuatro millones ochocientos mil pesos (\$834800 000). Para la zona occidente, que comprende las localidades de Fontibón, Teusaquillo, Barrios Unidos, Puente Aranda, Los Mártires, Kennedy y Bosa, las viviendas no sobrepasan los $90 \mathrm{~m}^{2}$ con un precio máximo de \$178 430000 . Finalmente en la zona sur, que comprende las localidades de Antonio Nariño, Rafael Uribe Uribe, San Cristóbal, Ciudad Bolívar, Tunjuelito y Usme, sus proyectos en venta no superan los $\$ 100000000$ y de igual forma, no alcanzan a llegar a los $80 \mathrm{~m}^{2}$.

Dicho análisis demuestra una clara sectorización en la ciudad en torno a la oferta de vivienda y su tamaño, ubicando hacia el sur y el occidente los proyectos más pequeños y de menor valor, que en su mayoría se clasifican en Vivienda de Interés Social. De esta manera es claro ver cómo los precios sobre las viviendas, que dependen de su ubicación sobre el espacio bogotano, generan una clara segregación socioespacial, en tanto las personas solo pueden comprar las viviendas donde les permite su capacidad económica, teniendo que asumir 
Bogotá: estrategias espaciales en la provisión de vivienda estal popular en un contexto neoliberal

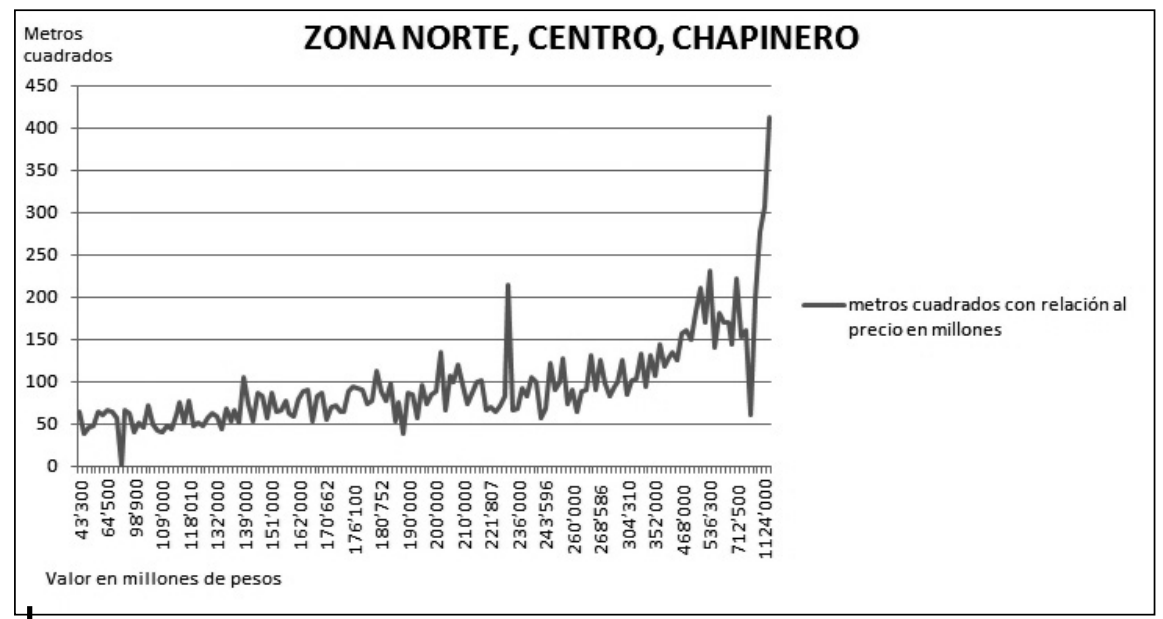

Figura 2 - Valor de la vivienda según área en metros cuadrados en la zona Norte, Centro y Chapinero

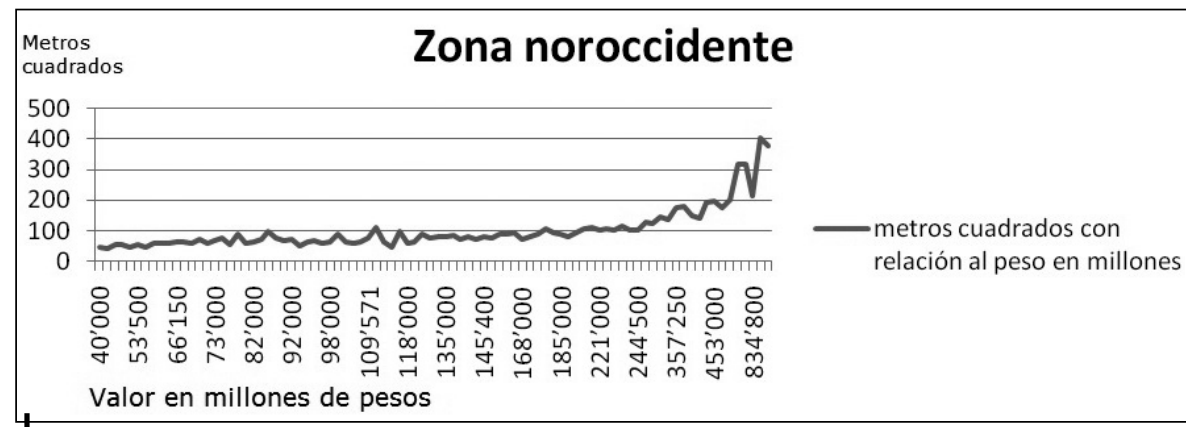

Figura 3 - Valor de la vivienda según metros cuadrados en la Zona Noroccidente

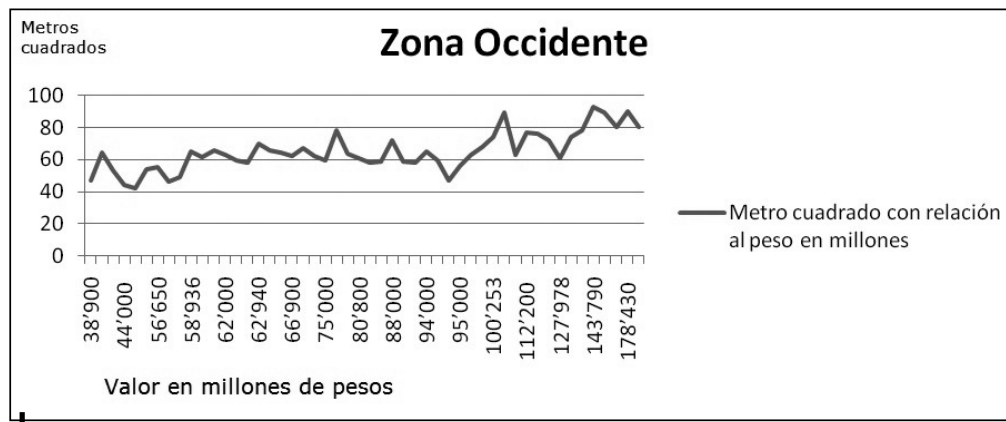

Figura 4 - Valor de la vivienda según metros cuadrados en la Zona Occidente 


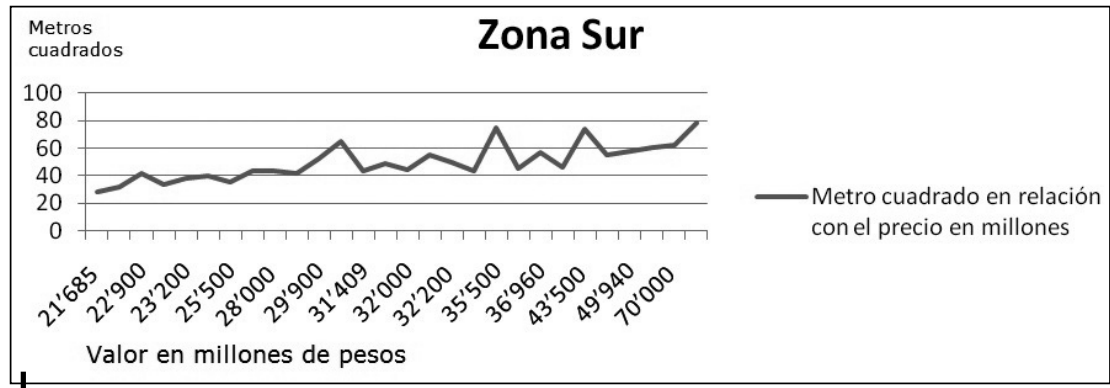

Figura 5 - Valor de la vivienda según metros cuadrados en la Zona Sur

casi obligatoriamente la ubicación de la misma y su tamaño. En este sentido, se evidencia una mayor libertad de escogencia del lugar y el tamaño de la vivienda en las familias con mayores recursos económicos, ya que las de ingresos bajos, solo pueden escoger en los lugares y los tamaños que su presupuesto les permite. En el siguiente diagrama de barras se presentan los datos anteriormente mencionados de la revista Metro cuadrado. De esta forma, se evidencia el promedio de metros cuadrados por zona, donde es clara la diferenciación entre las zonas del norte con las zonas del sur y occidente.

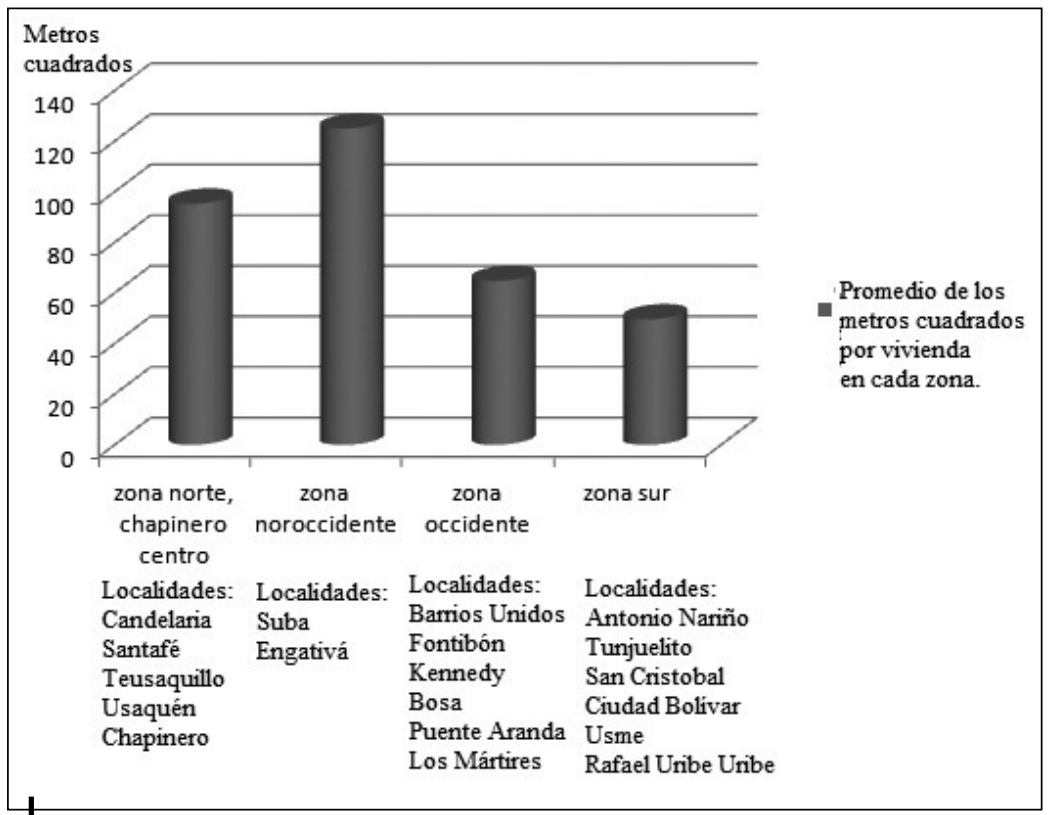

Figura 6 - Promedio de metros cuadrados de la vivienda según cada zona de la ciudad 
Desde la década de 1990, con la entrada del neoliberalismo y la apertura económica del país, se implementaron desde el Estado nuevas formas de acceder a la vivienda popular.

«Hasta 1991, el Estado colombiano impulsó una política de promoción de oferta, basada en la construcción y venta directa de viviendas realizadas a través de las entidades encargadas de tal función, el ICT, el BCH, el FNA y otras» (Molina, 2007: 1).

Después de esta fecha, la provisión de vivienda popular se caracterizó por un nuevo modelo de acceso, basado en los «subsidios a la demanda», ya no a la oferta, establecidos en la ley 3 de 1991 (Molina, 2007: 2), el cual se basa en un Subsidio Familiar de Vivienda, otorgado por el Estado a las familias de estratos bajos que pretende aumentar la demanda de la misma y con ello estimular la oferta desde los constructores.

Cambia de esta forma la direccionalidad del Estado en tanto se convierte en un ente facilitador que dentro de la política de provisión de vivienda da todas las garantías, como por ejemplo los subsidios a la demanda, las especificaciones mínimas de construcción de vivienda y la competencia entre los constructores (Dávila, 2006: 226). A su vez, la liquidación de las entidades estatales que se encargaban de la política de vivienda, como el Banco Central Hipotecario, el Instituto de Crédito Territorial, la Caja de Vivienda Popular y el Inurbe, abre las puertas al sector privado, el cual no solo capta la edificación de los proyectos habitacionales, sino que también aprovecha los subsidios a la demanda, los cuales en su mayoría son distribuidos actualmente por las cajas de compensación familiar. En este sentido

«las políticas neoliberales han enfatizado la iniciativa individual, transfiriendo responsabilidades a los agentes privados (empresas y ciudadanos) y dirigiendo el apoyo estatal al acceso individual a soluciones del mercado» (Dávila, 2006: 23).

Es de aclarar que todavía una parte reducida de estos subsidios es otorgada directamente por el Estado, básicamente a las familias que no se encuentran vinculadas formalmente al mercado laboral, en tanto las cajas de compensación familiar lo hacen con el sector laboralmente activo en el mercado formal.

Estos elementos se basan en la nueva Constitución Política, la cual establece en el artículo 51 de la Carta Política, como parte de los derechos sociales, económicos y culturales, que «todos los colombianos tienen derecho a vivienda digna. El Estado fijará las condiciones necesarias para hacer efectivo este derecho y promoverá planes de vivienda de interés social, sistemas adecuados de financiamiento a largo plazo y formas asociativas de ejecución de estos programas de vivienda», se destacan desde el Estado nuevas normativas que regulan tal provisión. Sobresale entonces el surgimiento del concepto de Vivienda de Interés Social VIS para el año de 1991, el cual se encuentra normativizado actualmente por el Decreto 4466 de 2007.

Dicho decreto reglamenta la VIS como «solución de vivienda cuyo valor máximo es de ciento treinta y cinco salarios mínimos legales mensuales vigentes» y la 
Vivienda de Interés Prioritario VIP como «solución de vivienda cuyo valor máximo es de setenta salarios mínimos legales mensuales vigentes». Entonces, en 2011 la VIS tiene un costo máximo de $\$ 72306$ 000, es decir, 41082 dólares, y la VIP de \$37 492 000, es decir, 21302 dólares. El mismo decreto reglamenta también al Subsidio Familiar de Vivienda SFV, el cual solo es otorgado para la adquisición de vivienda nueva y que tiene como parámetros para su adquisición, la obtención de puntos en relación con las siguientes variables:

1. Condiciones socioeconómicas de acuerdo con los puntajes del SISBEN3 que evidencien mayor nivel de pobreza.

2. Número de miembros del hogar.

3. Condiciones especiales de los miembros del hogar.

4. Ahorro previo.

5. Número de veces que el postulante ha participado en el proceso de asignación de subsidio, sin haber resultado beneficiario, siempre y cuando haya mantenido la inmovilización del ahorro mínimo pactado para la postulación (Ministerio de Ambiente, 2007).

En relación con las anteriores variables, se evidencian ciertos parámetros que impiden la libre adquisición de VIS o VIP para los sectores en condición de pobreza. El principal limitante es el ahorro previo que deben tener las familias al momento de postular al SFV que debe ser del 10 \% del valor de la solución de vivienda. Se hace claro entonces, cómo la oferta de vivienda para las clases populares no ofrece una verdadera alternativa para la mayoría, en tanto no pueden acceder a dicha oferta. En consecuencia deben recurrir a opciones informales de acceso a la vivienda, como lo es la urbanización pirata, la invasión de predios, o seguir de manera formal viviendo en arriendo, es decir, pagar un monto de dinero mensual por ocupar un espacio como una casa, o solo algunos cuartos en ella, como en los denominados inquilinatos, casas grandes que se arriendan por cuartos y que albergan a varias familias.

Teniendo en cuenta que el ahorro programado es un punto importante para poder acceder al SFV, el gobierno nacional lanzó el sistema del Fondo Nacional del Ahorro FNA para «impulsar y consolidar la cultura del ahorro y propiciar la incorporación al sistema financiero de la población no vinculada al mercado laboral formal» (Alcaldía Mayor de Bogotá, 2007: 12). En la actualidad, esta entidad se caracteriza por otorgar préstamos a través de ahorros programados, convirtiéndose en una alternativa para los hogares en busca de vivienda. Sin embargo, es de aclarar que si bien el FNA es una alternativa para un grueso de la población de estratos bajos, deja al margen a aquellas familias que por su precaria situación económica y laboral no pueden cumplir con las pautas de ahorro.

3 SISBEN es el Sistema de Identificación y Clasificación de Potenciales Beneficiarios para los programas sociales. Es una encuesta que sirve para identificar y clasificar a las personas que no pueden cubrir sus necesidades básicas para que el Estado pueda darles derechos fundamentales, subsidios que les permitan tener vivienda, educación y salud, entre otros. 


\section{PROVISIÓN DE VIS Y VIP EN EL DISTRITO CAPITAL}

En 1999 surge Metrovivienda, empresa social y comercial del Estado, «concebida como banco de tierras para proveer de suelo urbanizado a los sectores de bajos ingresos en condiciones de eficiencia y competitividad frente a la oferta informal de suelo» (Molina, 2007: 6). Metrovivienda, como entidad autosostenible, se encarga de la obtención de suelo urbanizable y su adecuación en infraestructura, para luego darlo a constructoras privadas que realizarán el proceso de construcción de las viviendas y permitirán recuperar la inversión hecha por la entidad, para asî iniciar un nuevo proceso urbanístico.

Los subsidios a la vivienda para los proyectos agenciados desde esta entidad son proveídos por el Programa Distrital de Subsidio de Vivienda para los trabajadores independientes, es decir, aquellos trabajadores que no se encuentran vinculados formalmente con ninguna empresa, y por las cajas de compensación familiar y Fonvivienda para los trabajadores formales. Metrovivienda maneja dentro de su oferta la clasificación de VIS tipo 1 y VIS tipo 2. La VIS tipo 1 tiene un precio de hasta 50 salarios mínimos legales vigentes. Para 2007 su valor era de 21685000 (veinte y un millones seis cientos ochenta y cinco mil pesos) (12 321dólares), en tanto que la VIS tipo 2 tiene un precio superior a los 50 y hasta 70 salarios mínimos legales vigentes: en 2007 su valor era de 30359000 (treinta millones trescientos cincuenta y nueve mil pesos) (17 249 dólares). Dicha clasificación según el decreto 4466 de 2007 corresponde a la VIP.

Los proyectos urbanísticos que ha agenciado esta entidad son los siguientes: Ciudadela el Recreo, que inició la venta de viviendas en 2000 y que en 2008 contaba con 11623 viviendas; ciudadela el Porvenir iniciado en 2003 con 12373 viviendas y aproximadamente 42068 habitantes para 2008 y el plan parcial Campo Verde en 2007 con 7189 viviendas propuestas, en la localidad de Bosa; y en la localidad de Usme la Ciudadela Nuevo Usme, que en 2007 contaba con 1044 casas construidas de un potencial de 4264 y con 4176 habitantes aproximadamente y el proyecto Usme Ciudad del Futuro, que en 2008 esperaba generar 36000 viviendas.

Para el caso de la operación estratégica Nuevo Usme, esta se presenta con un margen de intervención más amplio que los anteriores proyectos agenciados por Metrovivienda, en tanto incluye la dimensión socioecnonómica, físico-espacial, técnico-constructiva y ambiental territorial. Sin embargo, la institucionalidad desconoce el proceso de adquisición de terrenos para este proyecto, los cuales han sido comprados por cifras irrisorias a sus antiguos dueños, los campesinos del área rural de la localidad de Usme, quienes son los más perjudicados dentro de este proceso. El siguiente testimonio, ilustra tal situación:

«Pero lo poquito de tierra cultivable está en miras de ser expropiada para destinarla al sistema de vivienda popular. Eso ha sido un problema que muy pronto nos va a afectar. Esto se va a urbanizar, porque la ciudad recibe mucho desplazado y las entidades miran para el sur y deciden seguir construyendo y poblando estas zonas, que todavía tienen algo de ruralidad 
(testimonio de habitante del sector de Usme, noviembre de 2006) (Pérez et al., 2011: 89)

En el resto de la ciudad, sobresale la oferta hecha desde las cajas de compensación y las firmas constructoras, destacando aquí el papel de las Cajas de Compensación Familiar Compensar y Colsubsidio. La primera de ellas se destaca como un agente proveedor de subsidios de vivienda a diferentes proyectos que relaciona en su página web; la segunda, Colsubsidio, brinda subsidios de vivienda y a su vez presenta una considerable oferta de VIP y VIS entre la que se encuentran para 2011 los siguientes proyectos: Reserva Tayrona y Condominios el Porvenir en la localidad de Bosa; Condominios de Tierrabuena II e Ipanema en la localidad de Kennedy; Nueva Tierra Grata, Arces Rojos y Arces Azules en la localidad de Engativá. No se mencionan los proyectos de esta entidad en Soacha debido a que este trabajo se centra en el análisis del Distrito Capital (fig. 7)

Debido a los costos que manejan los proyectos de VIP y VIS, se acentúa su ubicación sobre los predios con estratos 1 y 2, si a esta situación se le agrega que los nuevos proyectos urbanísticos son ubicados en espacios sin urbanizar, se nota un proceso de periferización cada vez más marcado de las clases populares en la ciudad. Prefiriendo entonces para su construcción el occidente y sur de la ciudad.

Aunque las nuevas urbanizaciones de VIP y VIS cuentan con la infraestructura suficiente en malla vial, se evidencia una lejanía de estas en relación con las vías y avenidas principales además de la clara distancia con los centros económicos, culturales, de prestación de servicios y de fuentes de trabajo en la ciudad. Motivo por el cual las administraciones distritales han ubicado cerca de ellas nuevos colegios, parques y SUPER CADES. Es una forma de acercar a estas nuevas urbanizaciones los servicios prestados por el gobierno distrital y con ello dignificar los proyectos de vivienda. Sin embargo, se evidencia cómo la localización juega un papel importante sobre el valor de los lugares. Es entonces como los espacios periféricos de la ciudad se convierten en óptimos para la localización de proyectos de vivienda popular, y aunque tengan cerca algunos servicios básicos, son sus habitantes los que tienen que pagar el costo de su ubicación.

Para el caso de las urbanizaciones ubicadas en la localidad de Kennedy y presentadas en el mapa, la distancia hasta la avenida Ciudad de Cali, principal avenida que cuenta con la presencia de Transmilenio y otras rutas de buses, es tanta que surgió un submercado de movilización basado en bici-taxis y pequeñas camionetas blancas que cobran alrededor de \$1 000 pesos (50 centavos de dólar), por transportar a la gente desde sus residencias hasta la estación de Trasmilenio. De igual forma, la operación estratégica Nuevo Usme se encuentra muy retirada de dicho portal, ya que hace parte de la zona de expansión de la localidad de Usme y todavía en mayor parte se compone de suelos rurales en proceso de urbanización. Estas situaciones generan para los habitantes la duplicación de los costos de movilización hasta las fuentes de trabajo, ya que muchos de ellos deben desplazarse hacia el norte, noroccidente o centro de la ciudad.

Entonces, además de pagar el costo de una vivienda popular, los nuevos propietarios deben pagar el valor agregado de su localización, ya que el valor del 


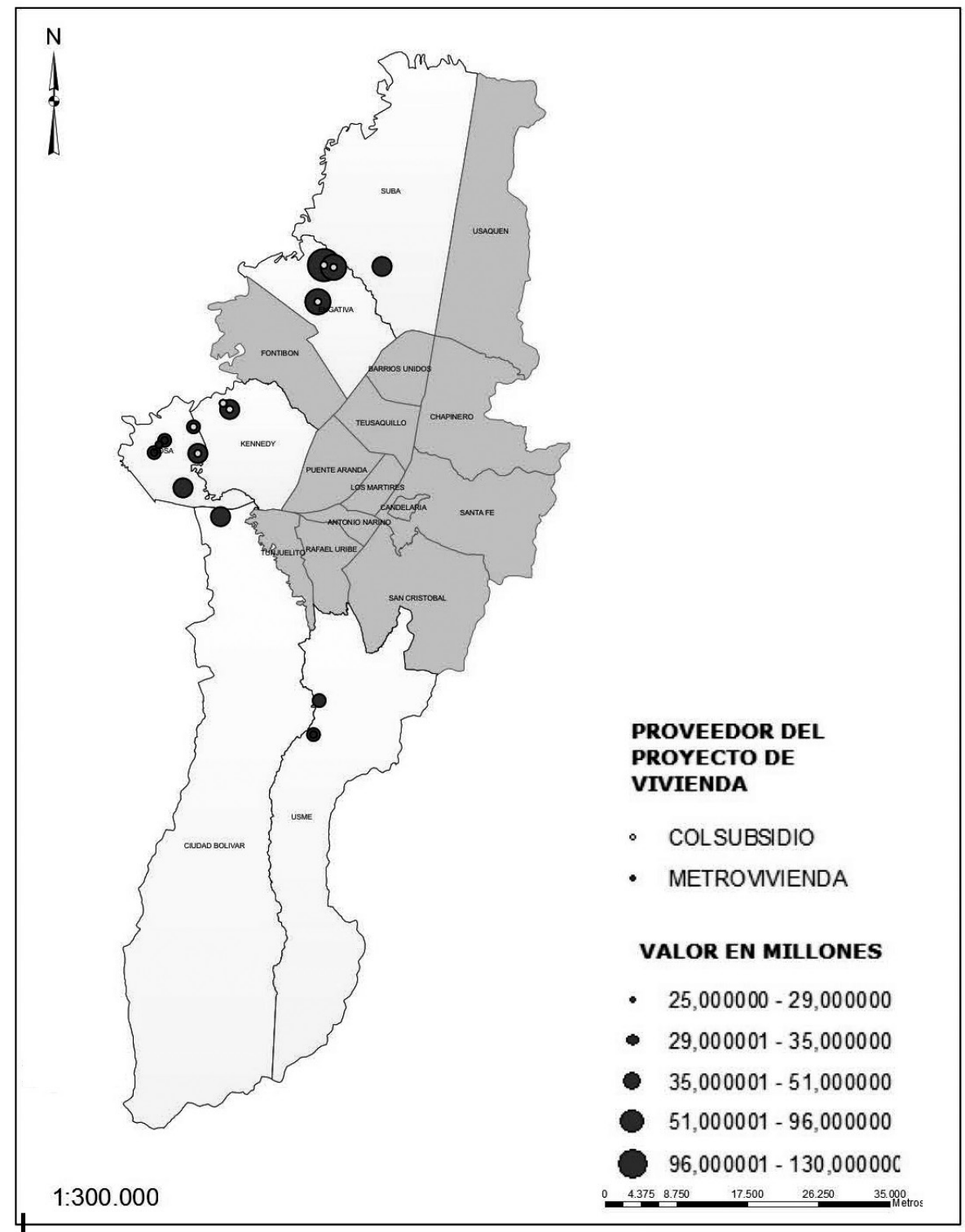

Figura 7 - Provedores de viviendas VIP y VIS en las localidades de De Bosa, Kennedy, Ciudad Bolívar, Usme, Suba y Engativa

pasaje en buses y el Trasmilenio oscila entre los 1450 y 1700 pesos (1 dólar). El costo del desplazamiento desde una de estas urbanizaciones hacia otro sitio de la ciudad, ida y vuelta, es entonces de aproximadamente 5000 pesos, es decir, 2,80 dólares. La distancia aproximada desde los proyectos de vivienda ubicados en las localidades de Kennedy, Bosa o Usme hacia el centro de Bogotá o el norte, es de 
alrededor de hora y media a dos horas; para el caso de Usme, su desplazamiento hacia el norte de la ciudad supera las dos horas. Igualmente y teniendo en cuenta los datos otorgados por la encuesta de movilidad en Bogotá se evidencia, cómo en las localidades periféricas de Suba Bosa, Ciudad Bolívar y Usme, los habitantes recorren más distancia en su desplazamiento, y de igual forma, gastan más tiempo en los viajes que los habitantes de otras localidades (Observatorio, 2005).

Otro aspecto de relevancia frente a las VIP y VIS es su calidad. Ya se tiene clara la alta disminución del tamaño de las viviendas; es así como las viviendas ofertadas por la caja de compensación de Colsubsidio oscilan entre los 40 y los $68 \mathrm{~m}^{2}$, en las cuales se siguen ubicando familias promedio de cinco a seis personas, restando con ello la calidad del espacio en cuanto a tamaño. Adicionalmente, se debe tener en cuenta también su fabricación. La empresa privada necesita ganar dinero con las viviendas construidas, y como debe ofrecerlas a un bajo costo, utiliza para su construcción materiales de baja calidad, e incluso las entrega sin los acabados finales: los pisos son impermeabilizados y se entregan sin baldosas y las paredes se entregan sin pañetar. En algunos casos estas viviendas se entregan con puertas en la entrada, en los baños y en el patio de ropas, no en las habitaciones.

En este sentido, se encuentra el siguiente aparte tomado del proyecto de «Suelo urbano y vivienda para la población de ingresos bajos» (Dávila et al., 2006: 155):

«En su afán por ofrecer una vivienda muy barata, la constructora descuida mucho la calidad, la impermeabilización de los techos es muy mala. También tenemos muchos problemas con los desagües en los caminos peatonales, porque los niveles están mal hechos, de manera se inundan y se encharcan. También comentaron insistentemente sobre la falta de privacidad debido a las servidumbres auditivas: convivo más con mi vecina que con mi esposo... Estos apuntes son solo una pequeña muestra que señala la ausencia de mecanismos efectivos de control de calidad en la oferta de VIS formal que garanticen unos estándares técnicos y habitacionales mínimos)».

A pesar de las condiciones de este tipo de viviendas, las familias acceden a ellas porque son la única oferta que avala el SFV. Así se nota cómo la provisión de vivienda dentro del neoliberalismo solo cubre una necesidad, brindar techo, descuidando la satisfacción de tener una casa a la medida de las necesidades familiares, o con sus acabados terminados. Las familias que acceden a este tipo de viviendas deben someterse al precio que genera su ubicación en la periferia así como al costo que genera la terminación, los acabados o la ampliación de su vivienda nueva.

\section{CONCLUSIONES}

Es notable el cambio de modelo económico sobre la provisión de vivienda. Si bien la cantidad de vivienda entregada durante el modelo keynesiano no alcazaba a satisfacer la demanda de las familias de la ciudad, presentaba un mayor tamaño y mejor calidad para sus habitantes, en tanto, al ser construidas y comercializadas por 
el Estado a través de sus diferentes empresas, su comercialización no era seguida de un interés por obtener ganancia. La meta principal de estas viviendas era solucionar los problemas habitacionales de los obreros y empleados de la ciudad.

Con el mismo objetivo, el de resolver los problemas habitacionales de los bogotanos, pero desde otros medios, se agencia la provisión de vivienda actualmente y desde 1991 en Bogotá. Marcada por el modelo neoliberal, la vivienda en la ciudad es producida por constructoras privadas, las cuales bajo el lema de obtener mayor ganancia a menor precio, aprovechan al máximo el espacio, ofreciendo viviendas de un área reducida incluso hasta los $32 \mathrm{~m}^{2}$, además de ahorrar en costos de materiales y acabados.

A pesar del stock de viviendas en oferta en Bogotá para las clases populares, y pese a los esfuerzos realizados por Metrovivienda y los estímulos generados desde el Estado, se sigue presentado en la ciudad un déficit habitacional generado básicamente por la poca cantidad, en relación con la demanda, de proyectos de VIS y VIP así como la insuficiencia de proyectos más inclusivos para la población a la que sus penurias económicas les impide realizar ahorros programados para acceder a algún tipo de viviendas. Todavía siguen siendo más atractivas para las familias de escasos recursos las ofertas realizadas desde los urbanizadores piratas, o los arriendos en barrios populares, que el acceso a vivienda nueva donde los costos mensuales en su mayoría son mucho más altos.

Con el fin de remediar dicha problemática, surgió en 2012 una iniciativa gubernamental que fue aprobada por el congreso colombiano y que pretende otorgar viviendas completamente gratuitas a las familias que no pueden acceder a ellas por no tener un ahorro previo, requisito para el subsidio de vivienda, ni contar con la capacidad de pago para la misma. De esta manera, la propuesta gubernamental propone 100000 nuevas viviendas VIP gratuitas que serán construidas en toda Colombia. Esta propuesta no deja de ser polémica, la cifra de familias que no pueden acceder a la vivienda formal por motivos económicos es mucho más alta que la cantidad de viviendas a construir. De igual manera se presentan falencias a la hora de contabilizar los recursos, ya que las cifras de dinero propuestas por el gobierno son calculadas según el presupuesto del año 2012, pero las viviendas serán canceladas a los constructores privados cuando estén completamente terminadas, es decir en un promedio de cuatro años. Es necesario entonces esperar la ejecución de dicha propuesta con el fin de analizarla cabalmente.

La localización de predios sin urbanizar en las periferias del sur y occidente de la ciudad es aprovechada por los constructores de VIP y VIS, que necesitan acceder a predios de bajo costo para así ofrecer viviendas económicas. De esta manera, son adquiridas grandes extensiones de terreno que por su cantidad ofrecen una mejor ventaja en tanto su precio es menor, y permiten la masificación de un mismo estilo de vivienda popular, con unas mismas características en diseño y materiales. Consecuentemente, se evidencia la brecha socioeconómica de los habitantes de la ciudad en su ubicación sobre la misma, los habitantes con menos recursos son los destinados a ocupar las periferias urbanas, en un estilo similar de 
casas y servicios, en relación con los centros económicos y culturales, ubicados hacia el oriente y norte de la ciudad.

La principal consecuencia del modelo neoliberal sobre la provisión de vivienda urbana es la delegación a la empresa privada de la construcción y venta de los proyectos habitacionales, impidiendo con esto el retorno de la totalidad de los recursos invertidos en la adecuación de los terrenos y la construcción de equipamientos de servicios. Sin embargo son los subsidios a la demanda los que significan mayor pérdida de dinero para el Estado, en tanto son dineros que se entregan a las familias para que puedan acceder a una vivienda y que estas a su vez los entregan a las empresas privadas, sin generar retribución sobre dichos dineros al Estado. Es de aclarar en esta parte, cómo las entidades financieras también se ven favorecidas con la construcción de vivienda popular, puesto que prestan el dinero sobre la hipoteca de la casa vendida. Para suplir el valor restante de la casa que no fue cubierto por el subsidio, las entidades financieras pasan a recibir mensualmente, por un periodo de quince años, los pagos según las crecientes tasas de interés.

\section{Referencias citadas}

ALZATE, M. C., 2006 - La estratificación socioeconómica para el cobro de los servicios públicos domiciliarios en Colombia isolidaridad o focalización?, 101 pp.; Bogotá: CEPAL. Serie Estudios y Perspectivas, n. ${ }^{\circ} 14$.

ALCALDÍA MAYOR DE BOGOTÁ, 2007 - Metrovivienda, guía para tener vivienda en un hábitat digno.

CHELA, 1997 - Miremos el Quiroga. Bogotá, Mimeo.

CCVL CORPORACIÓN COLEGIO DE VILLA DE LEYVA, 1996 - Estado, ciudad y vivienda: urbanismo y arquitectura de la vivienda estatal en Colombia, 1918-1990, 382 pp.; Bogotá: Inurbe.

COLSUBSIDIO, 2010 - Proyecto Maiporé.

Http://mesavis.uniandes.edu.co/Presentaciones\%202010/Proyecto\%20

maipore\%2029\%20abril.pdf

DE MATTOS, C., 2009 - Modernización capitalista y revolución urbana en América Latina: cinco tendencias genéricas. In: La ciudad Latinoamericana en el Siglo XXI: globalización, neoliberalismo, planeación (P. Brand, ed.): 37-50; Medellín: Universidad Nacional de Colombia.

DUREAU, F., BARBARY, O., GOUËSEST, V., PISSOAT, O. \& LULLE, T., 2007 - Ciudades y sociedades en mutación. Lecturas cruzadas sobre Colombia, 470 pp.; Bogotá: Universidad Externado de Colombia.

DÁVILA, J. et al., 2006 - Suelo urbano y vivienda para la población de ingresos bajos. Estudios de caso: Bogotá-Soacha-Mosquera; Medellín y Área metropolitana, 274 pp.; London: Development Planning Unit - DPU University College London.

ESPINOSA, L. D., 2007 - El Estado en la construcción de las áreas residenciales en Bogotá. In: Urbanismos. Áreas residenciales de Bogotá (J. Del Castillo, ed.): 56-73; Bogotá: Universidad Nacional de Colombia, Facultad de Artes. 
Bogotá: estrategias espaciales en la provisión de vivienda estal popular en un contexto neoliberal

ESPINOSA, M. A., 2009 - Perspectiva de la geografía crítica en el estudio de la ciudad colombiana contemporánea. In: Lecturas en teoría de la geografía (J. Montoya, ed.): 189-232; Bogotá: Universidad Nacional de Colombia.

HARVEY, D., 1985 - Urbanismo y desigualdad social, 335 pp.; Madrid: Siglo XXI editores.

HARVEY, D., 2001 - Espacios del capital, hacia una geografía crítica, 448 pp.; Madrid: Ediciones Akal.

HARVEY, D., 2007 - Breve Historia del Neoliberalismo, 256 pp.; Madrid: Ediciones Akal.

HIDALGO, R., 2011 - La urbanización de las áreas periféricas en Santiago y Valparaíso: el papel de las relaciones de poder en el dibujo de la geografía socioresidencial. Revista EURE, Vol 37, n. ${ }^{\circ}$ 111: 79-105.

JOLLY, J.-F., 2010 - Regir el territorio y gobernar los territorios: Políticas públicas de vivienda de interés social, servicios públicos domiciliario y educación en Colombia, 334 pp.; Bogotá: Pontificia Universidad Javeriana.

METROCUADRADO, 2007 - Proyectos en venta en Bogotá y sus alrededores. http:contenido.metrocuadrado.comcontenidom2publesp_m2revmetro_ esprevistam2octubre2007ARCHIVOARCHIVO-3655465-0.pdf

MINISTERIO DEL AMBIENTE VIVIENDA Y DESARROLLO TERRITORIAL, 2007 - Decreto Número 4466 de 2007, por el cual se reglamentan la Ley 3 de 1991, los artículos 83 y 86 de la Ley 1151 de 2007 y se dictan otras disposiciones.

MOLINA, I., 2007 - La vivienda en el desarrollo humano de Bogotá. El subsidio a la demanda, la calidad urbana y las ataduras del pensamiento. Revista digital Café de las Ciudades, año 6, $\mathbf{n} .^{\circ} \mathbf{5 5}$.

MORA, A., 2010 - El UPAC y la UVR: aspectos centrales sobre el origen y desarrollo del crédito hipotecario en Colombia. Revista MBA, n. ${ }^{\circ}$ 1: 12-27; Medellín: EAFIT.

OBSERVATORIO DE MOVILIDAD, 2005 - Encuesta de Movilidad; Bogotá: Cámara de Comercio de Bogotá.

PRADILLA COBOS, E., 2009 - Las políticas y la planeación urbana en el neoliberalismo. In: La ciudad Latinoamericana en el Siglo XXI: globalización, neoliberalismo, planeación (P. Brand, ed.): 287-307; Medellín: Universidad Nacional de Colombia.

PÉREZ MARTÍNEZ, M., VARGAS NAVARRO, F., BAUTISTA MACIA, M. \& BOHÓRQUEZ ALFONSO, I., 2011 - Pobladores y espacios rurales en la ciudad de Bogotá, la voz de los actores locales, 199 pp.; Bogotá: Pontificia Universidad Javeriana - Fundación Universitaria Agraria de Colombia.

TORRES TOVAR, C. A., 2009 - El hábitat popular en la ciudad (no) Globalizada. In: La ciudad Latinoamericana en el Siglo XXI: globalización, neoliberalismo, planeación (P. Brand, ed.): 259-282; Medellín: Universidad Nacional de Colombia.

TORRES TOVAR, C. A. \& RINCÓN GARCÍA J. J., 2011 - Suelo urbano y vivienda social en Bogotá: la primacía del mercado y el sacrifico del interés general, 1990-2010, 140 pp.; Bogotá: Universidad Nacional de Colombia.

VEGA CANTOR, R., 2007 - Un mundo incierto, un mundo para aprender y enseñar, 645 pp.; Bogotá: Universidad Pedagógica Nacional. 